\title{
Living with Diabetes: A Woman's Perspective
}

Bharti Kalra ${ }^{1}$

${ }^{1}$ Department of Obstetrics, Bharti Hospital, Karnal, Haryana, India

J Soc Health Diab 2019;7:91-93

\section{Introduction}

Being born a woman is a blessing: it brings with it that extra dose of resilience and strength, which helps one survive in a male-dominated world. Being a woman allows one to manage the various challenges and demands of living life. Though these challenges and demands increase manifold in patients with diabetes, women handle these responsibilities as part of life. Irrespective of which member of the family has diabetes, it takes a woman to manage diabetes.

I have a strong family history of diabetes and follow a strict lifestyle to keep the "metabolic wolf" at bay. I have seen diabetes at close quarters, both personally and professionally. Four generations of my family have diabetes, and I serve a large community of women, men, and children with the condition. I appreciate the efforts made by colleagues from India and abroad to study and resolve the psychosocial challenges that women with diabetes face. ${ }^{1-4}$ It is the insight gained through these experiences, which I present below.

\section{My Grandmother}

I must have been a few years old when my grandmother developed diabetes. I do not know what oral medication she took initially, but soon she was on insulin. This was in the mid-1970s. Milkhi Ram, a "registered medical practitioner" (RMP), would cycle down to our house twice a day, boil her glass syringe and thick-bored metallic needle, and inject her intramuscularly, in the hip. If these injections, delivered with blunt, reused needles hurt her, she never complained. She was grateful for the chance to live her life.

My grandfather also had diabetes, and life in our household revolved around this syndrome. I doubt if my grandparents worried about chronic vascular complications back then. Their main concerns were hypoglycemia (when the entire neighborhood would rush to feed my grandmother sweet meats) and lack of flexibility (no overnight trips for grandma, as no one in the family knew how to inject insulin). Another pressing issue was finance (a significant (proportion of the monthly income was set aside for insulin).

\begin{abstract}
Address for correspondence Bharti Kalra, Department of Obstetrics, Bharti Hospital, Kunjpura Road, Model Town, Near State Bank of India, Sector 12, Karnal 132001, Haryana, India (e-mail: dr.kalrabharti@gmail.com).
\end{abstract}

\section{Diabetic Diet}

I think my family tried its best to follow the advice given by (well meaning) doctors and self-styled "experts." When I look back, however, I shudder to think what state our metabolic health was in. Butter and clarified butter (ghee) were the center stage of our cuisine, which was based upon carbohydrate-rich cereals. My grandparents were not allowed to eat fruits and sweets, but there was no restriction on fried foods and ghee.

\section{My Mother}

The strong family history, coupled with inappropriate culinary habits, did have an impact on the next generation. One by one, most of my uncle and aunts developed type 2 diabetes. This list included my mother, who suddenly found she was losing weight and experiencing osmotic symptoms. She began using tablets prescribed by the local doctor, but I doubt if they helped her much.

I had become a medical student by then, but I do not think I learnt anything in college which helped my mother improve her glycemic control. There was no awareness of the targets for glucose control, of the need to avoid hypoglycemia, and of the importance of cardiovascular risk reduction.

\section{Diabetes Hearsay}

Every "expert," whether qualified or not, had a different take on diabetes cure. Newer cuisines and recipes were suggested, all of which created an extra load on the cook, that is, my mother. They advocated exotic treatments like concoctions of seeds and spices of dubious values. The general dictum seemed to be this: The greater the difficulty and expense in procuring an herbal treatment, the more beneficial its effect.

A similar scene was being played out at my uncles' and aunts' homes. Whenever they met, discussion would revolve around diabetes care, especially complementary and alternative medicine, ${ }^{5}$ and around cost of therapy. Everyone would received

July 12, 2019

accepted after revision

July 16, 2019
DOI https://doi.org/

$10.1055 / \mathrm{s}-0039-3400214$

ISSN 2321-0656.
O2019 Novo Nordisk Education Foundation
License terms

() (1) $\Theta \circledast$ 
then refresh themselves with a hearty meal or snack, cooked in true Punjabi style, and conclude with a philosophical "whatever will happen, will happen" statement.

\section{Insulin}

The inevitable did happen, and within a few years, the siblings had to shift to insulin. Insulin was a generic drug, prescribed twice daily, irrespective of the preparation. My mother began self-injecting, inspired by her younger brother, who had taken on the responsibility of administering insulin to their mother in her final days, after the RMP become too old to manage his rounds on bicycle.

Armed with my "foreign" pharmacology textbook, I learnt that basal and bolus insulin were different. It was then that my mother realized that the insulin she was using was cloudy at times, and clear at others. This set us off on a search for the correct doctor, who could prescribe the correct insulin regimen and preparation. This quest meant that insulin sometimes had to be sourced from a medical college located $90 \mathrm{~km}$ away from home. The responsibility of keeping our refrigerator stocked with insulin was taken up by my sister-in-law, who added insulin to the grocery list.

\section{Looking Back}

When I look back, I am not sure if we managed diabetes to the best of our ability. We did follow medical advice, and adhered to therapy, but did not bother about lifestyle modification. Perhaps our doctors did not emphasize the important of diet and exercise, perhaps we got conflicting advice which conflicting advice which confused us, or perhaps we just chose not to listen. Certainly, we could have done much better.

\section{Complications}

Hindsight is a great teacher, they say, but it cannot change the past. In a few years my mother (and one of her brothers) developed end-stage renal disease (ESRD). A few months on dialysis convinced us that a kidney transplant was her only option. My brother took 6 months off from work, and migrated to a distant city where transplants were done. My mother came back happy, but continued to have uncontrolled diabetes. By this time, newer insulin preparations and delivery devices had become available in our state. Our health care providers were able to explain the basics of dietary therapy, physical activity, stress management, and insulin usage. By following a disciplined lifestyle, my mother was able to survive for 10 years after her transplant. She finally succumbed to a seemingly innocuous foot ulcer, after a year-long battle. The emotional, social, and financial impact on our family is difficult to express in words; it will suffice to say that living with ESRD is a challenge which is better prevented, rather than experienced.

My uncle, too, had developed ESRD; unable to obtain a transplant, he opted for continuous ambulatory peritoneal dialysis (CAPD). The duty of handling this complex procedure fell on his arthritic wife, who managed her responsibility for
2 years, until he passed away. Another uncle's diabetes was complicated by premature cardiovascular disease. His children were not allowed the luxury of higher education, and had to begin working after graduating from college.

\section{My Generation}

As years went by, it was time for my cousins to develop dysglycemia. Type 2 diabetes, type 1 diabetes, gestational diabetes, and impaired glucose tolerance, all found a place in our large family. Medical care had improved by then, and so had its acceptance. Most of my cousins understand the importance of good glycemic control, adhere to therapy, and are complication free. The credit goes to the women of the family, who motivate the menfolk to exercise and follow medical advice, while ensuring a healthy larder for them.

\section{Generation Next}

The younger members of the family, that is, my nephews and nieces, have not been spared. Obesity, impaired glucose tolerance, and type 1 diabetes have gained a foothold in this generation as well. ${ }^{6}$ Their mothers struggle with competing social, emotional, and financial demand to provide a healthy culinary experience to their families. This is easier said than done, however.

\section{The Triple Challenge: Triple Strength}

In some cases, I find my aunt fighting a triple challenge of diabetes: type 2 diabetes in herself, gestational diabetes in the daughter-in-law, and type 1 diabetes in the grandchild. This triple challenge is associated with a triple burden: biomedical, psychosocial, and financial. In spite of such heavy demands, they live life with a smile. It is this resilience, this strength, this coping power, that is termed "woman power."

\section{My Profession}

As a diabetes care professional, I care for thousands of individuals with diabetes. I see them not as individuals, however, but as families, as part of a larger society. When a male patient presents with type 2 diabetes, I realize the effort his wife makes to provide tasty, wholesome, and healthy food. When an overweight adolescent is diagnosed with diabetes, I empathize with the mother's self-blame and guilt. If a child walks in with type 1 diabetes, I understand the pressure on her mother to learn diabetology overnight. When I see a newly married woman with freshly diagnosed gestational diabetes, I feel the tremors of fear of social ostracization that go through her.

In my clinic, these concerns weigh equally, alongside biomedical issues. ${ }^{7}$ It sometimes becomes a challenge to counsel irate patients, uncooperative family members, and "armchair diabetologist" friends. Countering diabetes hearsay, ${ }^{8}$ and promoting salutogenic messages becomes a herculean task. Balancing biomedical demands of an evidence-based system, with individualized psychosocial profiles also becomes tough, especially in a resource-challenged, time-constrained clinic. 


\section{My Inspiration}

At such times, I remember my grandmother, mother, and aunts. They lived with diabetes, and yet, they smiled. They lived a full life. If they could live happily with diabetes, I should be able to work happily with people who live with diabetes. It is this inspiration which keeps me going. It is this inspiration which makes me confident that women will win the war against diabetes. ${ }^{9}$

\section{Conflict of Interest}

None declared.

\section{References}

1 Bajaj S, Jawad F, Islam N, et al. South Asian women with diabetes: psychosocial challenges and management-consensus statement. Indian J Endocrinol Metab 2013;17(4):548-562

2 Kalra S, Coetzee A, Afsana F, et al. Gestational diabetes mellitus: Berlin and beyond. J Pak Med Assoc 2017;67(4):641-644
3 Kalra S, Sridhar GR, Balhara YP, et al. National recommendations: psychosocial management of diabetes in India. Indian J Endocrinol Metab 2013;17(3):376-395

4 Kalra B, Sridhar GR, Madhu K, Balhara YP, Sahay RK, Kalra S. Psychosocial management of diabetes in pregnancy. Indian J Endocrinol Metab 2013;17(5):815-818

5 Kesavadev J, Saboo B, Sadikot S, et al. Unproven therapies for diabetes and their implications. Adv Ther 2017;34(1):60-77

6 Kalra S, Kalra B, Sharma A. Prevalence of type 1 diabetes mellitus in Karnal district, Haryana state, India. Diabetol Metab Syndr 2010;2(1):14

7 Kalra B, Kalra S, Bajaj S. Vulvodynia: an unrecognized diabetic neuropathic syndrome. Indian J Endocrinol Metab 2013;17(5):787-789

8 Kalra S, Balachandran K. De-hearsay (diabetes e-hearsay). J Pak Med Assoc 2017;67(8):1293-1295

9 Kalra S, Malik S, John M. Gestational diabetes mellitus: a window of opportunity. Indian J Endocrinol Metab 2011;15(3):149-151 